\title{
Anaplastic meningioma: an analysis of the National Cancer Database from 2004 to 2012
}

\author{
Andrew Orton, MD, ${ }^{1}$ Jonathan Frandsen, MD, ${ }^{1}$ Randy Jensen, MD, PhD, ${ }^{2}$ \\ Dennis C. Shrieve, MD, PhD, ${ }^{1}$ and Gita Suneja, MD, MSHP1 \\ Departments of ${ }^{1}$ Radiation Oncology and ${ }^{2}$ Neurosurgery, University of Utah, Salt Lake City, Utah
}

OBJECTIVE Anaplastic meningiomas represent $1 \%-2 \%$ of meningioma diagnoses and portend a poor prognosis. Limited information is available on practice patterns and optimal management. The purpose of this study was to define treatment patterns and outcomes by treatment modality using a large national cancer registry.

METHODS The National Cancer Database was used to identify patients diagnosed with anaplastic meningioma from 2004 to 2012. Log-rank statistics were used to compare survival outcomes by extent of resection, use of adjuvant radiotherapy (RT), and use of adjuvant chemotherapy. Least-squares linear regression was used to evaluate the utilization of RT over time. Logistic regression modeling was used to identify predictors of receipt of RT. Cox proportional hazards modeling was used to evaluate the effect of RT, gross-total resection (GTR), and chemotherapy on survival.

RESULTS A total of 755 adults with anaplastic meningioma were identified. The 5 -year overall survival rate was $41.4 \%$. Fifty-two percent of patients received RT, $7 \%$ received chemotherapy, and $58 \%$ underwent GTR. Older patients were less likely to receive RT (OR 0.98, $p<0.01$ ). Older age (HR 1.04, $p<0.01)$, high comorbidity score (HR 1.33, $p=0.02)$, and subtotal resection (HR 1.57, $p=0.02$ ) were associated with increased risk of death on multivariate modeling, while $\mathrm{RT}$ receipt was associated with decreased risk of death (HR $0.79, p=0.04)$. Chemotherapy did not have a demonstrable effect on survival (HR 1.33, $p=0.18$ ).

CONCLUSIONS Anaplastic meningioma portends a poor prognosis. Gross-total resection and RT are associated with improved survival, but utilization of RT is low. Unless medically contraindicated, patients with anaplastic meningioma should be offered RT.

https://thejns.org/doi/abs/10.3171/2017.2.JNS162282

KEY WORDS anaplastic meningioma; radiotherapy; surgery; chemotherapy; patterns of care; oncology

$\mathrm{M}$ ENINGIOMAS are common intracranial tumors for which resection and/or radiation therapy represent the mainstays of treatment. ${ }^{21}$ The World Health Organization (WHO) classification scheme for pathological diagnosis of meningioma is widely considered the gold standard for differentiating between benign, atypical, and anaplastic meningiomas (Grades I, II, and III, respectively). ${ }^{19-21}$ The WHO published their initial classification scheme in 1993, followed by major revisions in 2000 and minor revisions in 2007. ${ }^{20,21}$

Anaplastic meningiomas represent only $1 \%-2 \%$ of meningioma diagnoses and portend a poor prognosis. ${ }^{11,21,32,35}$ The definition of an anaplastic meningioma (according to the 2007 WHO classification) includes: $\geq 20$ mitoses per 10 high-power fields; anaplastic (malignant) cytology re- sembling that of carcinoma, melanoma, or high-grade sarcoma; or predominant papillary or rhabdoid morphology. For anaplastic meningioma, the outcomes literature after the $2000 \mathrm{WHO}$ classification change is sparse and consists mainly of small, retrospective case series. ${ }^{17,8,10,22,27,29,30,32,36}$

The purpose of this study was to define current patterns of care in the United States and to evaluate the utility of adjuvant radiotherapy (RT) and chemotherapy, as well as the impact of extent of surgery, as they relate to survival in anaplastic meningioma.

\section{Methods}

The patients included in this analysis were identified from the National Cancer Database (NCDB), a hospital-

ABBREVIATIONS GTR = gross-total resection; HR = hazard ratio; ICD-O-3 = International Classification of Diseases for Oncology, Third Edition; NCDB = National Cancer Database; $\mathrm{OR}=$ odds ratio; $\mathrm{RT}=$ radiotherapy; $\mathrm{STR}=$ subtotal resection; WHO = World Health Organization.

SUBMITTED August 30, 2016. ACCEPTED February 2, 2017.

INCLUDE WHEN CITING Published online July 21, 2017; DOI: 10.3171/2017.2.JNS162282. 
based cancer registry capturing approximately $70 \%$ of cancer diagnoses in the United States. ${ }^{25}$ Hospitals that are approved by the American College of Surgeons' Commission on Cancer and participate in the NCDB are expected to provide follow-up data and data regarding adjuvant treatment on at least $90 \%$ of all known living patients annually. ${ }^{4}$

Patients with a diagnosis of meningioma were identified using International Classification of Diseases for Oncology, Third Edition (ICD-O-3) codes 9530, 9531, 9533, and 9532. The World Health Organization (WHO) grading of tumors was taken from the variable "cs_sitespecific_factor_1"; this variable is coded using the WHO classification system for tumors of the central nervous system, so the actual histological diagnosis directly correlates with the histological grade of the tumor. This histological grade is not the same code that is assigned as the differentiation code in the sixth digit of the ICD-O morphology code and recorded in the traditional registry "grade" field, and must be taken from a pathology report (a value cannot be assigned based on imaging alone). Data were available for patients diagnosed between the years 2004 and 2012. Patients were excluded from analysis if follow-up data were unavailable, tumor grade was unknown, surgery was not performed, or neoadjuvant or intraoperative RT was performed.

Demographic and clinical covariates included for analysis were age, sex, race, Charlson-Deyo comorbidity score, ${ }^{12}$ facility type, tumor size, use of adjuvant RT, extent of resection, and receipt of adjuvant chemotherapy. A patterns-of-care analysis was performed with receipt of RT as the outcome of interest. Least-squares linear regression was performed to test for trends in RT utilization over the study period. Rates of RT utilization were compared between geographic regions using chi-square statistics and visualized using a choropleth map.

A univariate logistic regression model was applied to each covariate to estimate an odds ratio (OR) for receipt of RT. A multivariate logistic regression model was then developed using a reverse-stepwise elimination process; all covariates were included in an initial model, after which each covariate with a $\mathrm{p}$ value greater than 0.2 was removed in a reverse-stepwise fashion. ${ }^{6}$ Results from the final multivariate model were reported as ORs. A subgroup analysis was performed to compare survival based on extent of resection, use of RT, and use of chemotherapy, using logrank statistics.

Next, the effect of RT following surgery was examined. Patients were stratified by extent of resection and grouped by use or omission of RT. Univariate and multivariate Cox proportional hazards regression models were then applied in the same manner as outlined above. For the logistic and Cox proportional hazards models, missing data were imputed using the multivariate imputation by chained equations (MICE) method. ${ }^{3,23}$ Survival data were included in the imputation models using the Nelson-Aalen estimator. ${ }^{2,34}$ A p value less than 0.05 was considered significant. Stata version 14 was used for the analysis (StataCorp LLC).

Because all patient data were obtained from patient medical records (retrospectively), per NCDB reporting guidelines, the requirement for informed consent was waived. The study was submitted to our institutional review board and deemed exempt from review.

\section{Results}

The query resulted in 61,716 patients with a diagnosis of meningioma between the years 2004 and 2012. Seven hundred fifty-five tumors were anaplastic $(2.2 \%), 2198$ were atypical $(6.5 \%)$, and 31,006 (91.3\%) were benign. The overall 5-year survival rate for patients with anaplastic tumors was $41.4 \%$.

A summary of demographic and clinical characteristics of patients with anaplastic meningioma is given in Table 1 . The patients' median age was 65 years. The sex distribution was evenly split (50\% male and 50\% female). Gross-total resection (GTR) was achieved in $58 \%$ of patients, while $42 \%$ had either a subtotal resection (STR) or biopsy only. Fifty-two percent of patients received RT, and only $7 \%$ received chemotherapy.

TABLE 1. Demographic and clinical characteristics of patients with anaplastic meningioma

\begin{tabular}{|c|c|}
\hline Characteristic & Value \\
\hline \multicolumn{2}{|l|}{ Age in yrs } \\
\hline Median & 65 \\
\hline IQR & $55-74$ \\
\hline \multicolumn{2}{|l|}{ Sex } \\
\hline Male & $380(50)$ \\
\hline Female & $375(50)$ \\
\hline \multicolumn{2}{|l|}{ Race } \\
\hline White & $556(75)$ \\
\hline Black & $103(14)$ \\
\hline Hispanic & $51(7)$ \\
\hline Other & $36(5)$ \\
\hline \multicolumn{2}{|l|}{ Charlson-Deyo score } \\
\hline 0 & $535(71)$ \\
\hline $1+$ & $220(29)$ \\
\hline \multicolumn{2}{|l|}{ Facility type } \\
\hline Academic/research program & $360(51)$ \\
\hline Nonacademic/research program & $348(49)$ \\
\hline \multicolumn{2}{|l|}{ Tumor size in $\mathrm{cm}$} \\
\hline Median & 5 \\
\hline IQR & $3.8-6.1$ \\
\hline \multicolumn{2}{|l|}{ RT } \\
\hline No & $357(48)$ \\
\hline Yes & $389(52)$ \\
\hline \multicolumn{2}{|l|}{ EOR } \\
\hline GTR & $174(58)$ \\
\hline STR & $125(42)$ \\
\hline \multicolumn{2}{|l|}{ Chemo } \\
\hline No & $682(93)$ \\
\hline Yes & $49(7)$ \\
\hline
\end{tabular}

Chemo = chemotherapy; EOR = extent of resection; IQR = interquartile range; STR = subtotal resection (includes biopsy-only cases).

Data are presented as number of patients (\%) unless otherwise indicated. 


\section{Patterns of Care}

Rates of RT use ranged from $39 \%$ to $60 \%$ per year, with a trend toward increased RT utilization over time, which did not meet statistical significance (Fig. $1, \mathrm{p}=0.05$ ). There was significant $(\mathrm{p}<0.01)$ variation in utilization by geographic region, with rates varying from a high of $74 \%$ (West North Central region) to a low of 25\% (West South Central region, Fig. 2). The results of the analysis investigating patterns of care for RT receipt are summarized in Table 2. On both univariate and multivariate analysis, only receipt of chemotherapy (OR 4.56, $\mathrm{p}<0.01)$ predicted $\mathrm{RT}$ use. Increasing age (OR $0.98, \mathrm{p}<0.01)$ and comorbidity score of 1 or greater (OR 0.49, $\mathrm{p}<0.01)$ predicted omission of RT.

\section{Survival Analysis}

Kaplan-Meier curves depicting survival in patients grouped by receipt of RT, extent of resection, and use of chemotherapy are shown in Panels A, B, and C of Fig. 3 , respectively. Receipt of RT was associated with improved survival (log-rank $\mathrm{p}<0.01$ ), while achieving a GTR showed a trend toward improved survival, which did not meet significance (3-year survival was $63.1 \%$ for those undergoing GTR vs $53.4 \%$ for those undergoing STR, logrank $\mathrm{p}=0.06$ ). Chemotherapy did not appear to affect survival ( $\log$-rank $\mathrm{p}=0.68$ ); however, the number of patients in this group was limited. The effect of the combination of the extent of resection and use of RT is shown in Fig. 3D; the best outcomes were obtained in patients who achieved a GTR and received RT, while those who did not achieve a GTR and did not receive RT fared the worst (log-rank p $<0.01$ ). If a patient underwent an STR, survival was improved with the addition of RT (log-rank $\mathrm{p}<0.01)$. Survival among those who underwent STR and received RT and those who had a GTR and did not receive RT did not differ significantly (log-rank $\mathrm{p}=0.28)$.

Results of the univariate and multivariate Cox proportional hazards regression model are reported in Table 3. On multivariate modeling, increasing age (hazard ratio [HR] 1.04, p < 0.01) and higher comorbidity score (HR $1.33, \mathrm{p}=0.02$ ) remained significantly associated with risk of death; additionally, achieving an STR was also found to put a patient at higher risk of death (HR 1.57, $\mathrm{p}=0.02)$.

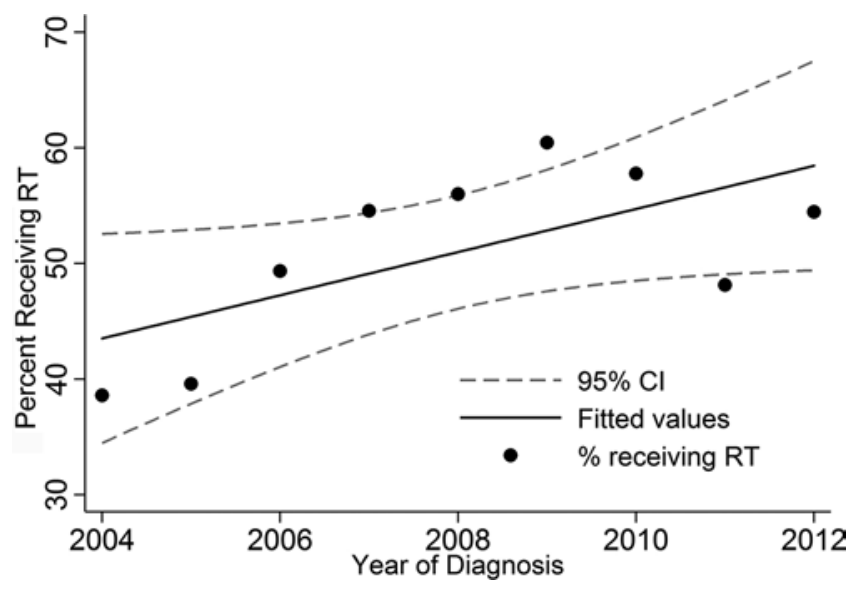

FIG. 1. Trends in RT utilization over the study period.

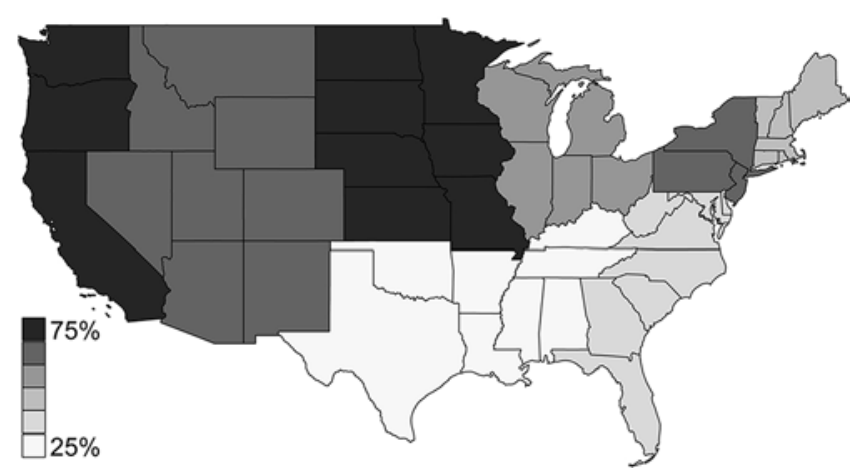

FIG. 2. A choropleth map showing rate of adjuvant RT use by geographical region. Hawaii and Alaska are not depicted due to space constraints, but they are included with California, Oregon, and Washington in the NCDB.

Receipt of RT continued to be associated with decreased risk of death in the multivariate model (HR 0.79, $\mathrm{p}=0.04)$. Chemotherapy did not have a demonstrable effect on survival in univariate (HR 1.08, $\mathrm{p}=0.70$ ) or multivariate modeling (HR 1.33, $\mathrm{p}=0.18)$.

\section{Discussion}

Using patient data from the $\mathrm{NCDB}$, the current analysis

TABLE 2. Predictors of adjuvant RT receipt by univariate and multivariate logistic regression

\begin{tabular}{|c|c|c|c|c|c|c|}
\hline \multirow[b]{2}{*}{ Factor } & \multicolumn{3}{|c|}{ Univariate } & \multicolumn{3}{|c|}{ Multivariate } \\
\hline & OR & $95 \% \mathrm{Cl}$ & $p$ Value & OR & $95 \% \mathrm{Cl}$ & p Value \\
\hline Age & 0.98 & $0.97-0.99$ & $<0.01$ & 0.98 & $0.97-0.99$ & $<0.01$ \\
\hline \multicolumn{7}{|l|}{ Sex } \\
\hline Male & 1.00 & - & - & & & \\
\hline Female & 0.94 & $0.71-1.25$ & 0.67 & & & \\
\hline \multicolumn{7}{|l|}{ Race } \\
\hline White & 1.00 & - & - & 1.00 & - & - \\
\hline Black & 0.74 & $0.49-1.14$ & 0.17 & 0.81 & $0.52-1.27$ & 0.36 \\
\hline Hispanic & 0.92 & $0.52-1.64$ & 0.78 & 0.80 & $0.44-1.48$ & 0.49 \\
\hline Other & 0.57 & $0.35-1.38$ & 0.30 & 0.58 & $0.28-1.18$ & 0.13 \\
\hline \multicolumn{7}{|l|}{$\begin{array}{l}\text { Comorbidity } \\
\text { score }\end{array}$} \\
\hline 0 & 1.00 & - & - & 1.00 & - & - \\
\hline $1+$ & 0.45 & $0.33-0.62$ & $<0.01$ & 0.49 & $0.35-0.68$ & $<0.01$ \\
\hline \multicolumn{7}{|l|}{ Facility type } \\
\hline Academic & 1.00 & - & - & & & \\
\hline $\begin{array}{r}\text { Nonaca- } \\
\text { demic }\end{array}$ & 1.08 & $0.80-1.45$ & 0.61 & & & \\
\hline Tumor size & 1.01 & $1.00-1.02$ & 0.08 & 1.20 & $1.00-1.02$ & 0.12 \\
\hline \multicolumn{7}{|l|}{ EOR } \\
\hline GTR & 1.00 & - & - & & & \\
\hline STR & 0.88 & $0.55-1.42$ & 0.61 & & & \\
\hline \multicolumn{7}{|l|}{ Chemo } \\
\hline No & 1.00 & - & - & 1.00 & - & - \\
\hline Yes & 5.26 & $2.43-11.41$ & $<0.01$ & 4.56 & $2.06-10.10$ & $<0.01$ \\
\hline
\end{tabular}

Boldface type indicates statistical significance. 
A

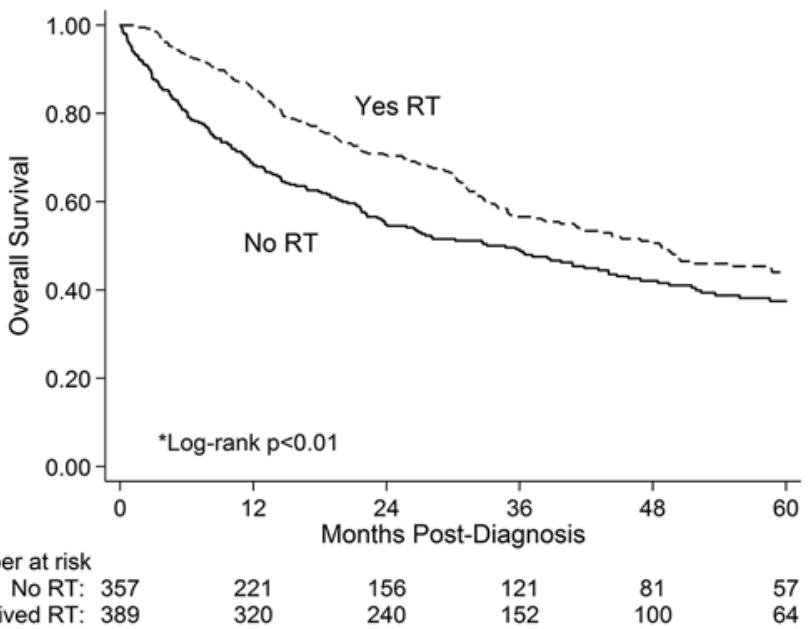

B

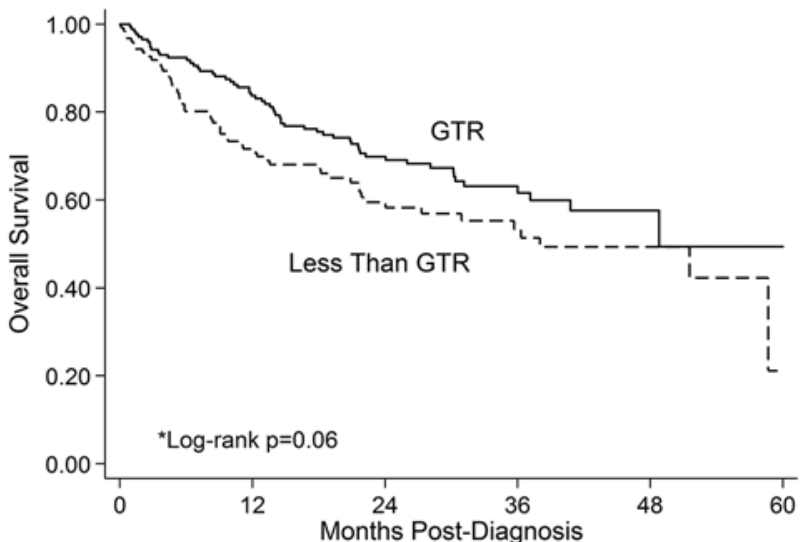

Number at risk

Months Post-Diagnosis

$$
\text { GTR: } 174
$$

Sub GTR: 125

133

133
81

91

49

42

7

10

1

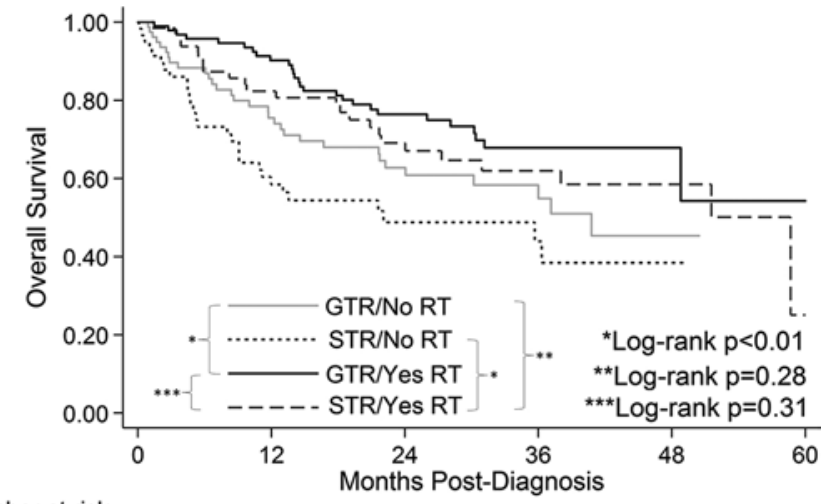

Number at risk

GTR/No RT: $79 \quad 51$

STR/No RT: $59 \quad 30$

GTR/Yes RT: 93

STRYes RT: 64

$\begin{array}{cc}33 & 17 \\ 15 & 9 \\ 57 & 25 \\ 34 & 19\end{array}$

FIG. 3. Subgroup analysis of the effect of RT (A), extent of resection (B), and chemotherapy (C) on survival in patients with anaplastic tumors. The interaction between RT and extent of resection is also shown (D). STR includes biopsy-only cases.

has shown that survival following diagnosis of anaplastic meningioma is superior for patients undergoing GTR and for those who receive adjuvant RT. There was no survival benefit shown for receipt of chemotherapy. Surprisingly, the rate of RT utilization was low, with less than $60 \%$ of patients receiving RT in the study cohort, but appears to be increasing. This analysis is the first to identify a survival benefit for GTR in WHO Grade III meningioma since the revised diagnostic classification was proposed by the WHO.

Previously reported studies have not shown a survival benefit for GTR, but they were likely underpowered. . $^{1,8,13,27 \text {, }}$ ${ }^{29,36}$ The result showing the importance of GTR is intuitive, as larger studies with adequate power in Grade II tumors have shown a survival benefit. ${ }^{15,16,22,31}$ Given the very poor prognosis associated with anaplastic tumors demonstrated in this analysis, it is concerning that GTR was achieved in only $58 \%$ of cases. This may in part be due to the extent of disease at the time of diagnosis of these aggressive tumors; when possible, however, GTR should be attempted.

The addition of RT to surgery improved the survival rate in patients with anaplastic meningioma. This outcome adds support to existing literature suggesting a survival benefit of adjuvant RT following surgery. ${ }^{13,24,27,29,30,36}$ The addition of RT was beneficial in both the setting of STR and the setting of GTR in the current study. Given the strong support in the literature for the addition of RT for anaplastic tumors, the low utilization rates observed in this study are concerning. The utilization findings are concordant with results reported by McCarthy et al., ${ }^{24}$ who showed a 36\% RT utilization rate. Especially concerning was the finding in the patterns-of-care analysis that STR did not predict for addition of RT to the therapy course, as these patients did demonstrate improved survival with addition of RT in the outcomes analysis. The decreased use of RT in the elderly noted in the present study has also been noted in other disease sites,,$^{5,9,14,26,33}$ and may be related to generally lower performance status in older patients and greater pessimism regarding life expectancy in general for patients with more age-related medical comorbidities. Encouragingly, utilization rates do appear to be increasing over time.

The geographic disparity in the rate of adjuvant RT use suggests that regional care patterns, rather than adherence to clear national guidelines, are driving adjuvant treatment decisions. This may be related to the lack of clear Level 1 evidence from a randomized trial supporting the addition 
TABLE 3. Univariate and multivariate Cox proportional hazards models estimating for survival

\begin{tabular}{|c|c|c|c|c|c|c|}
\hline \multirow[b]{2}{*}{ Factor } & \multicolumn{3}{|c|}{ Univariate } & \multicolumn{3}{|c|}{ Multivariate } \\
\hline & HR & $\begin{array}{c}95 \% \\
\mathrm{Cl}\end{array}$ & $\begin{array}{c}p \\
\text { Value }\end{array}$ & $\mathrm{HR}$ & $\begin{array}{c}95 \% \\
\mathrm{Cl}\end{array}$ & $\begin{array}{c}p \\
\text { Value }\end{array}$ \\
\hline Age & 1.04 & $1.03-1.04$ & $<0.01$ & 1.04 & $1.03-1.05$ & $<0.01$ \\
\hline \multicolumn{7}{|l|}{ Sex } \\
\hline Male & 1.00 & - & - & & & \\
\hline Female & 0.95 & $0.77-1.16$ & 0.59 & & & \\
\hline \multicolumn{7}{|l|}{ Race } \\
\hline White & 1.00 & - & - & & & \\
\hline Black & 0.83 & $0.60-1.14$ & 0.25 & & & \\
\hline Hispanic & 0.63 & $0.38-1.04$ & 0.07 & & & \\
\hline Other & 0.95 & $0.59-1.53$ & 0.83 & & & \\
\hline \multicolumn{7}{|l|}{$\begin{array}{l}\text { Comorbidity } \\
\text { score }\end{array}$} \\
\hline 0 & 1.00 & - & - & 1.00 & - & - \\
\hline $1+$ & 1.53 & $1.24-1.90$ & $<0.01$ & 1.33 & $1.05-1.67$ & 0.02 \\
\hline \multicolumn{7}{|l|}{ Facility type } \\
\hline Academic & 1.00 & - & - & & & \\
\hline Nonacademic & 1.16 & $0.94-1.43$ & 0.18 & & & \\
\hline Tumor size & 1.01 & $1.00-1.01$ & 0.09 & 1.01 & $1.00-1.01$ & 0.08 \\
\hline \multicolumn{7}{|l|}{ RT } \\
\hline No & 1.00 & - & - & 1.00 & - & - \\
\hline Yes & 0.70 & $0.57-0.86$ & $<0.01$ & 0.79 & $0.63-0.99$ & 0.04 \\
\hline \multicolumn{7}{|l|}{ EOR } \\
\hline GTR & 1.00 & - & - & 1.00 & - & - \\
\hline STR & 1.44 & $0.99-2.10$ & 0.06 & 1.57 & $1.06-2.31$ & 0.02 \\
\hline \multicolumn{7}{|l|}{ Chemo } \\
\hline No & 1.00 & - & - & 1.00 & - & - \\
\hline Yes & 1.08 & $0.73-1.59$ & 0.70 & 1.33 & $0.88-2.01$ & 0.18 \\
\hline
\end{tabular}

Boldface type indicates statistical significance.

of adjuvant RT. These regional variations may be expected to narrow upon publication of the results of RTOG 0539, a national Phase II trial of observation for low-risk meningiomas and of radiotherapy for intermediate- and highrisk meningiomas.

The finding that the use of chemotherapy failed to demonstrate a survival benefit is consistent with previously reported data regarding the limited utility of chemotherapy for this tumor type..$^{17}$ It is important to note, however, that the number of patients receiving chemotherapy in this cohort was low and the NCDB lacks the granularity to identify antiangiogenic tyrosine kinase inhibitors, which have been previously shown to impart modest benefit. ${ }^{18,28}$

The key strength of this study is the large number of cases identified using a large, national, hospital-based cancer registry. Additionally, the NCDB contains data on chemotherapy use, a variable that is not captured in other large cancer registries. Our results are subject to the limits of a retrospective database review, including lack of centralized pathological review, lack of standardization in surgical or RT techniques, and potential selection bias in treatment modalities offered. Some data are missing from the NCDB, an issue that we addressed statistically by using multiple imputation methodologies. Cause-specific death is not reported in this database, so death due to other comorbidities (e.g., heart disease) could not be analyzed. Finally, performance status was not available in this data set and may influence candidacy for adjuvant therapy.

\section{Conclusions}

Patterns of care and outcomes are reported for anaplastic meningioma using the NCDB for patients treated in the modern era. Anaplastic meningioma has a very poor prognosis; the estimated 5-year survival ranges from $45 \%$ for patients undergoing both GTR and RT to as low as 37\% for patients with an STR and no RT. A survival benefit for both GTR and addition of RT to surgery was observed. Chemotherapy did not appear to affect survival outcomes. The rate of RT utilization was low, with less than $60 \%$ of patients receiving RT in the study cohort, and shows wide geographic variation, but it appears to be increasing overall.

\section{Acknowledgments}

The NCDB is a joint project of the Commission on Cancer $(\mathrm{CoC})$ of the American College of Surgeons and the American Cancer Society. The CoC's NCDB and the hospitals participating in the CoC NCDB are the source of the deidentified data used herein; they have not verified and are not responsible for the statistical validity of the data analysis or the conclusions derived by the authors.

We would like to acknowledge the assistance of Michelle Denney in copyediting and submitting this article for publication.

\section{References}

1. Adeberg S, Hartmann C, Welzel T, Rieken S, Habermehl D, von Deimling A, et al: Long-term outcome after radiotherapy in patients with atypical and malignant meningiomas-clinical results in 85 patients treated in a single institution leading to optimized guidelines for early radiation therapy. Int $\mathbf{J}$ Radiat Oncol Biol Phys 83:859-864, 2012

2. Bartlett JW, Frost C, Carpenter JR: Multiple imputation models should incorporate the outcome in the model of interest. Brain 134:e189-e190, 2011 (Letter)

3. Beesley LJ, Bartlett JW, Wolf GT, Taylor JM: Multiple imputation of missing covariates for the Cox proportional hazards cure model. Stat Med 35:4701-4717, 2016

4. Bilimoria KY, Stewart AK, Winchester DP, Ko CY: The National Cancer Data Base: a powerful initiative to improve cancer care in the United States. Ann Surg Oncol 15:683690, 2008

5. Bouchardy C, Rapiti E, Blagojevic S, Vlastos AT, Vlastos G: Older female cancer patients: importance, causes, and consequences of undertreatment. J Clin Oncol 25:1858-1869, 2007

6. Budtz-Jørgensen E, Keiding N, Grandjean P, Weihe P: Confounder selection in environmental epidemiology: assessment of health effects of prenatal mercury exposure. Ann Epidemiol 17:27-35, 2007

7. Chan AW, Bernstein KD, Adams JA, Parambi RJ, Loeffler JS: Dose escalation with proton radiation therapy for highgrade meningiomas. Technol Cancer Res Treat 11:607614, 2012

8. Choi Y, Lim DH, Jo K, Nam DH, Seol HJ, Lee JI: Efficacy of postoperative radiotherapy for high grade meningiomas. J Neurooncol 119:405-412, 2014 
9. Clark LH, Jackson AL, Gehrig PA, Bae-Jump V, Van Le L, Ko EM: Adjuvant treatment and clinical trials in elderly patients with endometrial cancer: a time for change? Int $\mathbf{J}$ Gynecol Cancer 26:282-289, 2016

10. Combs SE, Kessel K, Habermehl D, Haberer T, Jäkel O, Debus J: Proton and carbon ion radiotherapy for primary brain tumors and tumors of the skull base. Acta Oncol 52:15041509,2013

11. Combs SE, Schulz-Ertner D, Debus J, von Deimling A, Hartmann C: Improved correlation of the neuropathologic classification according to adapted world health organization classification and outcome after radiotherapy in patients with atypical and anaplastic meningiomas. Int J Radiat Oncol Biol Phys 81:1415-1421, 2011

12. Deyo RA, Cherkin DC, Ciol MA: Adapting a clinical comorbidity index for use with ICD-9-CM administrative databases. J Clin Epidemiol 45:613-619, 1992

13. Durand A, Labrousse F, Jouvet A, Bauchet L, Kalamaridès M, Menei P, et al: WHO grade II and III meningiomas: a study of prognostic factors. J Neurooncol 95:367-375, 2009

14. Farina P, Lombardi G, Bergo E, Roma A, Zagonel V: Treatment of malignant gliomas in elderly patients: a concise overview of the literature. BioMed Res Int 2014:734281, 2014

15. Hardesty DA, Wolf AB, Brachman DG, McBride HL, Youssef E, Nakaji P, et al: The impact of adjuvant stereotactic radiosurgery on atypical meningioma recurrence following aggressive microsurgical resection. J Neurosurg 119:475481, 2013

16. Hueng DY, Li YF, Sytwu HK: Atypical meningiomas. J Neurosurg 120:781, 2014

17. Kaley T, Barani I, Chamberlain M, McDermott M, Panageas $\mathrm{K}$, Raizer J, et al: Historical benchmarks for medical therapy trials in surgery- and radiation-refractory meningioma: a RANO review. Neuro Oncol 16:829-840, 2014

18. Kaley TJ, Wen P, Schiff D, Ligon K, Haidar S, Karimi S, et al: Phase II trial of sunitinib for recurrent and progressive atypical and anaplastic meningioma. Neuro Oncol 17:116121,2015

19. Kleihues L, Lenz O, Bernhard M, Buhrke T, Friedrich B: The $\mathrm{H}_{2}$ sensor of Ralstonia eutropha is a member of the subclass of regulatory [NiFe] hydrogenases. J Bacteriol 182:27162724, 2000

20. Kleihues P, Burger PC, Scheithauer BW: The new WHO classification of brain tumours. Brain Pathol 3:255-268, 1993

21. Louis DN, Ohgaki H, Wiestler OD, Cavenee WK, Burger PC, Jouvet A, et al: The 2007 WHO classification of tumours of the central nervous system. Acta Neuropathol 114:97-109, 2007

22. Mair R, Morris K, Scott I, Carroll TA: Radiotherapy for atypical meningiomas. J Neurosurg 115:811-819, 2011

23. Marshall A, Altman DG, Holder RL, Royston P: Combining estimates of interest in prognostic modelling studies after multiple imputation: current practice and guidelines. BMC Med Res Methodol 9:57, 2009

24. McCarthy BJ, Davis FG, Freels S, Surawicz TS, Damek DM, Grutsch J, et al: Factors associated with survival in patients with meningioma. J Neurosurg 88:831-839, 1998

25. Mohanty S, Bilimoria KY: Comparing national cancer registries: The National Cancer Data Base (NCDB) and the Surveillance, Epidemiology, and End Results (SEER) program. J Surg Oncol 109:629-630, 2014
26. Parise CA, Bauer KR, Caggiano V: Disparities in receipt of adjuvant radiation therapy after breast-conserving surgery among the cancer-reporting regions of California. Cancer 118:2516-2524, 2012

27. Pollock BE, Stafford SL, Link MJ, Garces YI, Foote RL: Stereotactic radiosurgery of World Health Organization grade II and III intracranial meningiomas: treatment results on the basis of a 22-year experience. Cancer 118:1048-1054, 2012

28. Raizer JJ, Grimm SA, Rademaker A, Chandler JP, Muro K, Helenowski I, et al: A phase II trial of PTK787/ZK 222584 in recurrent or progressive radiation and surgery refractory meningiomas. J Neurooncol 117:93-101, 2014

29. Rosenberg LA, Prayson RA, Lee J, Reddy C, Chao ST, Barnett GH, et al: Long-term experience with World Health Organization grade III (malignant) meningiomas at a single institution. Int J Radiat Oncol Biol Phys 74:427-432, 2009

30. Sughrue ME, Sanai N, Shangari G, Parsa AT, Berger MS, McDermott MW: Outcome and survival following primary and repeat surgery for World Health Organization Grade III meningiomas. J Neurosurg 113:202-209, 2010

31. Sun SQ, Cai C, Murphy RK, DeWees T, Dacey RG, Grubb RL, et al: Management of atypical cranial meningiomas, part 2: predictors of progression and the role of adjuvant radiation after subtotal resection. Neurosurgery 75:356-363, 2014

32. Sun SQ, Hawasli AH, Huang J, Chicoine MR, Kim AH: An evidence-based treatment algorithm for the management of WHO Grade II and III meningiomas. Neurosurg Focus 38(3):E3, 2015

33. Truong PT, Kader HA, Lacy B, Lesperance M, MacNeil MV, Berthelet E, et al: The effects of age and comorbidity on treatment and outcomes in women with endometrial cancer. Am J Clin Oncol 28:157-164, 2005

34. White IR, Royston P: Imputing missing covariate values for the Cox model. Stat Med 28:1982-1998, 2009

35. Yang SY, Park CK, Park SH, Kim DG, Chung YS, Jung HW: Atypical and anaplastic meningiomas: prognostic implications of clinicopathological features. J Neurol Neurosurg Psychiatry 79:574-580, 2008

36. Zhao P, Hu M, Zhao M, Ren X, Jiang Z: Prognostic factors for patients with atypical or malignant meningiomas treated at a single center. Neurosurg $\operatorname{Rev} 38: 101-107,2015$

\section{Disclosures}

Dr. Jensen reports a consultant relationship with Pharmacokinesis and Medtronic.

\section{Author Contributions}

Conception and design: Orton, Frandsen, Suneja. Acquisition of data: Orton. Analysis and interpretation of data: all authors. Drafting the article: Orton. Critically revising the article: all authors. Reviewed submitted version of manuscript: all authors. Approved the final version of the manuscript on behalf of all authors: Orton. Statistical analysis: Orton. Study supervision: Orton, Jensen, Shrieve, Suneja.

\section{Correspondence}

Andrew Orton, Department of Radiation Oncology, University of Utah, 1950 Circle of Hope, Salt Lake City, UT 84112. email: andrew.orton@hci.utah.edu. 